\title{
A conversation with Carla Shatz
}

$\mathbf{N}_{\mathrm{c}}$ eurobiologist Carla Shatz (Figure 1), the director of Stanford University Bio-X, has focused her research on how early brain circuits are transformed into adult connections during critical periods of development. Her work, which focuses on the development of the mammalian visual system, has relevance not only for treating disorders such as autism and schizophrenia, but also for understanding how the nervous and immune systems interact. The full interview, with insights about what you can you learn from ski racing and how she got inspired to study neuroscience after her grandmother's stroke, can be seen on the JCI website, http://www.jci.org/kiosk/cgm.

JCI: What were your parents like?

Shatz: My dad was an aeronautical engineer and a mathematician, and my mom was a painter. I learned from an early age to love both science and art, and I also learned that it was okay for a girl to be a scientist. My dad was involved in the space race. Many of the things that he was working on were top secret, but we could talk about the excitement of the engineering challenges and his work in designing guidance systems for the lunar landing module. At the same time, my mother, my brother, and I would go to the museums, and we became quite knowledgeable. Their influence made it really hard for me to figure out what I wanted to do when I grew up.

JCI: When did you decide to focus on chemistry?

Shatz: I went to Radcliffe (now Harvard), not knowing quite what I was going to do. I love science fiction and thought I'd become an astrophysicist. But I didn't find it that exciting. I took a class in chemistry from an absolutely fabulous professor, and it fired me up. At the same time, I was also taking design courses. The way they came together was somewhat unexpected because I took a course in my junior year on the chemistry of vision. It was taught by George Wald, who had just won the Nobel Prize for his work understanding how the proteins in your eye absorb light and transduce a signal that is eventually converted to

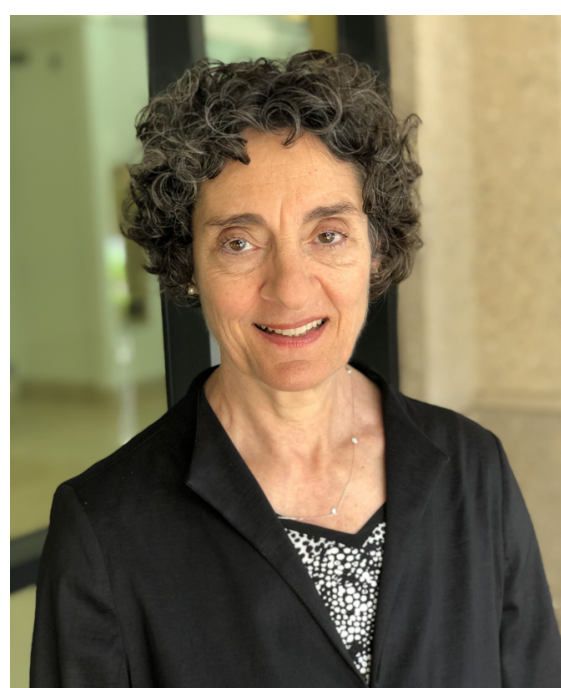

Figure 1. Carla Shatz on June 30, 2018 in Stanford, CA. Image credit: Ushma Neill.

a neural signal. He had been studying the chemistry of rhodopsin and how it undergoes a conformational change when light is absorbed. At the end of that course, I started thinking about how we see and how does the brain process visual information? And how is it that we can have these amazing perceptions that we appreciate in art? In particular, why is it that colors aren't constant, but that they get modulated by their location and their adjacent color environment in artworks?

Those questions brought me to my chemistry professor; I had to choose a lab for my senior honors thesis. He could have gotten really pissed off when I told him I didn't really like chemistry. But he was great and told me about two new professors at Harvard Medical School who were just setting up a lab, trying to study how the brain processes visual information coming from the eyes David Hubel and Torsten Wiesel. Of course, later, they received the Nobel Prize in Physiology or Medicine for their exploration of the visual pathways. Long story short, it was an eye-opening experience for me. It represented the synthesis of my two interests, science and chemistry on the one hand and art and visual perception on the other hand.
JCI: You then did a master's degree (MPhil) in England as a Marshall Scholar.

Shatz: Well, that was one of the best times of my life. I didn't decide to do a Marshall Scholarship. The dean of Radcliffe told me I'd be a good candidate, and it was a good intervention because I didn't know what I wanted to do next. I knew I wanted to study the brain, but I also knew that I did not want to go to medical school.

Hubel and Wiesel, my undergraduate honors thesis advisers, suggested that I might want to go to University College London (UCL) because there was a lot of very exciting work being done there on the nervous system. They actually wrote on my behalf to several people at UCL, including Ricardo Miledi and Bernard Katz, and said, "Would you take Carla if she got a Marshall Scholarship?" And they said yes. It was funny because, when I arrived as a Marshall Scholar, they'd forgotten that they had made a commitment to me for two years. That was very rapidly fixed, but it was pretty funny that when I got there, they said, "What are we going to do with her?" But it was an amazing time, and I learned about human physiology.

JCI: Did you know at that point you were going to go on to graduate school?

Shatz: Yes. I was going to go to Rockefeller for grad school and set it all up. But I always ask for advice, even if I don't always take it. And one person that I asked for advice was a neuroscientist at UCL, Semir Zeki. I was out to lunch with him one day, and he asked what I was going to do. I think he wanted me to stay and do a PhD at UCL, but I realized the training there was very different because people were already so specialized and I needed to take a few more courses to give me a grounding in fundamentals of neuroscience. Semir told me I was crazy to go to Rockefeller if I had an opportunity to go back to Harvard to work with Hubel and Wiesel, which was pretty prescient, since they did not have their Nobel Prize yet. So I wrote to them, and they said, "Sure, come back, no problem." And then I got a second letter saying, "Oh, by the way, I think you have to apply."

I was the first female to complete the degree and graduate from the program. There had been another woman before 
me who did not complete, and I was told much later that there was great concern about whether they should try out another one of us.

JCI: After a productive PhD studying the function of the visual system and your postdoc with Pasko Rakic studying early brain development, you moved to Stanford as one of the first female faculty hired in the basic sciences.

Shatz: I wrote my first research grant to the NIH and I got it, and that was the expected situation at the time. Now, when I look at it, I doubt that I would have gotten it today; it would have been very high risk for the NIH. They had some faith in me, as I think they should always have in junior investigators. With a very small start-up package from the university and a really significant NIH grant, I was off and running for five years.

I was establishing my identity as a woman scientist, and there were two aspects to that. The first was, "What do I wear to work?" Silly, I bring it up because I kept having the experience of being in my own lab and having the Zeiss microscope sales guy come into lab, look at the two women in the lab and say, "Where's Dr. Shatz?" I decided to wear slacks and a jacket to the lab.

The other thing was to develop a rapport with my colleagues and also the staff of the department itself. At that time, the entire support staff sat together in the middle of the building. My assistant was there too, and they were thrilled that there was finally a female assistant professor in the department. One day I was working with my assistant, and the phone rang, and she said, "Dr. Shatz, Dr. Charles Gilbert from Rockefeller University is on the phone and he says it's urgent. Would you like to take the call out here, or in your office?" I'm thinking, "I'll just take it out here, in front of them. He's probably going to ask me for some eigenfunction value of something or other, and I can show off." So, Charles says to me, "Carla, I must get your borscht recipe."

I gave the borscht recipe while looking at the crestfallen faces of all these women. From that day on, I've never taken calls in public, always in my office. Anyhow, it is a really good borscht recipe (Supplemental File 1; supplemental material available online with this article; https://doi.org/10.1172/ JCI123942DS1), and we used to exchange recipes all the time because we used to cook together as Harvard graduate students.

\section{JCI: You moved to Berkeley — why?}

Shatz: I had received tenure at Stanford, and I was very happy there, but my husband at the time was looking for jobs also. He was offered a job at UC Berkeley, and in those days, I think maybe even now, it was much more common for women to follow their husbands. So I moved to UC Berkeley, since there was a marvelous job there for me too, and we were working on trying to have kids at the time.

Actually, my infertility doctor was at a hospital in Oakland right next door to Berkeley. This was way before there were good ways of handling infertility. I always predicted that I would have a family and be married, and I would never have expected the kind of wonderful scientific life that I have had. But what I've learned is, life never goes the way you plan it. We moved together, and this was a very tough time for us both emotionally as we couldn't have children, and it led eventually to our divorce. I'm happy to share this because I have a lot of advice about how to deal with the challenges of trying to start a family while you're also trying to start or maintain a really great career. And often the two are very difficult to do together.

JCI: While you were at Stanford and then Berkeley, you made some of the discoveries that you're best known for: the retina creates waves of electrical activity even in utero, and the main molecular drivers of the signaling are molecules previously thought only to belong to the immune system.

Shatz: It was a hugely productive time in the lab, even if it wasn't reproductively productive for me, personally. At first, there was a huge amount of skepticism about our discoveries. We were really interested in the interaction between nature and nurture in brain wiring, and it had been shown that the connections from the eye to the brain are highly organized when you look at the adult pattern of connectivity. Because of this precision, it had been assumed that the connections from the retina to the brain had to be hardwired from the very beginning. We learned how to do experiments to study the very early development of these connections, even in utero, in animal models. We could label the growing nerve connections from the eye into the brain and discovered that the adult precise connections are not present initially. Instead, precision emerges over time as the connections remodel, so we next asked what the underlying mecha- nisms that drive the remodeling process are. That's when we discovered that the eye was autodialing spontaneously generating neural signals and sending them into the brain to test the connections and remodel them. That led us to identify what the underlying molecular mechanisms were that drive the remodeling process, another set of experiments nobody believed at first.

JCI: You're at this peak productivity, debunking dogma and changing the textbooks. Why go to Harvard to become chair of Neurobiology?

Shatz: There were two reasons. I loved my training in the Department of Neurobiology. The environment was extremely healthy and even though there were no "women-tors" at the time, there were great men and I felt that this was a chance to give back. The department needed to be rejuvenated. Also, it was a huge opportunity as a woman to be the first chairwoman of a Harvard Medical School basic science department. I gave up a lot by leaving California, but I gained a lot by going back to Boston.

JCI: After nine terrific years at Harvard, you came back to Stanford to be the director of Bio-X.

Shatz: I like to joke that if I tell you what the $\mathrm{X}$ is, I have to kill you. I came back because of this nascent program that was attempting an integration of disciplines. The idea is to encourage collaborative interdisciplinary research at the interface of all biology plus medical science, chemistry, physics, electrical engineering, mechanical engineering, chemical engineering, computer science. Bio-X is like a kind of a horizontal grid that's built across the pillars of the university, trying to unite them and to break down silos. It seemed really exciting to me. I've never looked back.

JCI: What other vocation do you think would have kept you happy?

Shatz: I can't answer that question. I'm so happy doing what I'm doing, it's almost inconceivable to me. But perhaps ski racer, ballet dancer, or maybe architect. Thank God I didn't become an architect because in science when you have an experiment fail, you go home, you wake up the next morning, and you do it again. In architecture, the building falls down. I don't think that would have been a good career for me, but I very much admire architects.

\section{Ushma S. Neill}

